\title{
INTERFACE TECNOLOGIAS DIGITAIS NO ENSINO DE QUÍMICA E ALFABETIZAÇÃO CIENTÍFICA: O QUE RELATAM OS ARTIGOS CIENTÍFICOS?
}

\author{
INTERFACE DIGITAL TECHNOLOGIES IN CHEMISTRY TEACHING AND \\ SCIENTIFIC LITERACY: WHAT DO SCIENTIFIC ARTICLES REPORT?
}

DOI: http://dx.doi.org/10.23926/RPD.2526-2149.2019.v4.n2.p621-640.id490

\section{Camila de Fatima Sant'Ana \\ Doutorado em andamento em Educação em Ciências e Saúde (UFRJ) \\ santana_camila@yahoo.com. $\underline{b r}$}

\author{
Denise Leal de Castro \\ Doutora em Química \\ (UFRRJ) \\ denise.castro@ifrj.edu.br
}

Resumo: Alguns documentos de políticas educacionais apontam a necessidade de oferta de uma educação no ensino médio tendo como instrumento as tecnologias de informação e comunicação e estruturado na formação crítico-social do educando, além da cognitiva, para sua posterior participação na sociedade de forma a cooperar na resolução de problemas sociais. Esta pesquisa apresenta resultados de uma análise qualitativa categorizada realizada em artigos científicos que relatam experiências de atividades que fomentaram a alfabetização científica no ensino de Química auxiliada por tecnologias digitais. Para tal, foi realizada uma busca no portal de Periódicos Capes entre os períodos de 2011 a 2018, utilizando palavras-chaves específicas que convergiam com o objetivo dessa pesquisa. Objetivou-se identificar como estes professores procuraram atender as diretrizes indicadas nestes documentos de políticas educacionais brasileiras. Observou-se que os autores destes artigos analisados contextualizaram os conteúdos de Química com temas sociais diversos, seus objetivos de contribuir na formação crítica-reflexiva foram granjeados. Entretanto as tecnologias digitais utilizadas ainda são pouco diversificadas.

Palavras-chave: Tecnologias digitais; Ensino de Química; Alfabetização científica; Formação de professores.

\begin{abstract}
Some educational policy documents point to the need to offer high school education based on information and communication technologies and structured in the critical-social formation of the learner, as well as cognitive, for their later participation in society in order to cooperate in education. solving social problems. This research presents results of a categorized qualitative analysis performed in scientific articles that report experiences of activities that fostered scientific literacy in chemistry teaching aided by digital technologies. To this end, a search was carried out in the Capes Periodicals portal from 2011 to 2018, using specific keywords that converged with the objective of this research. The objective was to identify how these teachers tried to meet the guidelines indicated in these Brazilian educational policy documents. It was observed that the authors of these articles analyzed contextualized Chemistry contents with diverse social themes, their objectives of contributing to the critical-reflexive formation were won. However the digital technologies used are still little diversified. Keywords: Digital technologies; Chemistry teaching; Scientific Literacy; Teacher training.
\end{abstract}




\section{INTRODUÇÃO}

É importante salientar que no contexto educacional brasileiro, os professores de Química precisam estar preparados para suscitar em suas aulas a formação cidadã dos educandos, não restringindo a práxis docente a transmissão de conteúdos, como é considerado por Freire (1987) de forma crítica de educação bancária. Chassot (2003), Krasilchic e Marandino (2004) focalizam para a relevância dos educandos adquirirem leitura crítica do mundo, e serem agentes de mudanças desse mundo em que estão agregados a partir da contextualização de conteúdos curriculares e temas sociais de seu cotidiano.

Incorpora-se neste viés a necessidade de compreensão de como está ocorrendo esta (trans)formação acadêmico crítico social no ensino médio, uma vez que os educandos apresentam dificuldades com a disciplina de Química, considerando esta de difícil entendimento e muito abstrata. Santos et. al. (2013) apontam que o ensino de Química geralmente é arquitetado em torno de tarefas que levam à memorização de informações, fórmulas e conteúdos teóricos dos quais os alunos não compreendem a necessidade de estudar estes conteúdos.

Adiantando-se o progresso tecnológico, assoma-se no início da década de 1990 a internet, considerada nos dias atuais como imprescindível no cotidiano da sociedade que tem sua vida facilitada em muitos aspectos, tais como otimização do tempo, buscas e pesquisas em geral. Resultando da utilização da internet em massa, torna-se progressivo o emprego de Tecnologias Digitais de Informação e Comunicação (TDIC) como recursos didáticos por educadores e estudantes, tais como blogs, sites interativos, simuladores, aplicativos de celular, jogos digitais, dentre outros, que promovem conhecimento e socialização segundo Baranauskas e Valente (2013). Isto posto Nascimento, Fernandes e Mendonça (2010, p. 228) salientam que "o desenvolvimento científico e tecnológico mundial e brasileiro exerceu e vem exercendo forte influência sobre o ensino de Ciências".

Utilizando esses recursos em sala de aula os professores têm como objetivo minimizar as dificuldades de aprendizado dos educandos, bem como oportunizar uma maior interação social professor-aluno. Sobre este viés, Santos et al. (2007) apontam que

\footnotetext{
A difusão do computador na escola promove um avanço no processo de ensinoaprendizagem dos alunos, uma vez que as pessoas vivem num mundo altamente dependente dos aparelhos tecnológicos para sua sobrevivência, e a educação não foge a regra. $\mathrm{O}$ uso intensivo da internet se mostrou uma obrigatoriedade para dinamizar tanto os conteúdos curriculares dos alunos em formação como a educação ao longo da vida para os profissionais recém-saídos das universidades (SANTOS et al., 2007, p. 4).
} 
Os estudantes recebem com aprazibilidade os recursos didáticos digitais, pois estão inseridos e familiarizados a era digital. Esta é uma condição propícia para o incentivo da utilização de alguns dispositivos digitais pelos educadores. Nesta perspectiva Leite (2015, p. 239) cita que "a tecnologia atual tem permitido criar material didático usando multimídias e interatividade que tornam mais efetivos os ambientes de ensino e aprendizagem".

É importante que estes profissionais por sua vez, conheçam com propriedade os dispositivos digitais, dominando a mediação da utilização dos mesmos em suas aulas, a fim de proporcionar aos educandos o entendimento de conteúdos da disciplina de Química, e tornando a atividade didática produtiva. Além de favorecer na formação social e crítica dos mesmos a partir de temas do cotidiano como apontam Chassot (2003) e Freire (1987). Isto posto, Vieira e Restivo (2014, p. 5) ressaltam que "o papel do docente foi redefinido e a sua missão deixou de ser ensinar matéria, mas ensinar a aprender".

Ao elucubrar sobre a prática docente, destaca-se a importância da sua constante (trans)formação em muitos aspectos, não somente o acadêmico, posto que as mudanças ocorram com muita rapidez na contemporaneidade. Neste sentido Pretto e Riccio (2010) destacam que

\footnotetext{
Se o professor não viver plenamente a experiência da cibercultura e se não conhecer e experimentar as possibilidades e potencialidades das redes digitais, todo o investimento que o país faz na montagem destas redes, não passará de uma parafernália a serviço de uma educação centrada em superadas práticas educacionais, que seguramente não dará conta dos desafios do país no século XXI (PRETTO e RICCIO, 2010, p. 166).
}

É indispensável à constante atualização do professor sobre a utilização das TDIC, de forma que ele possa promover além dos conhecimentos curriculares, a reflexão do educando para desenvolver autonomia na tomada de decisão e posição crítica sobre contextos sociais. Libâneo (2011) salienta a necessidade atual de uma formação para a cidadania crítica, onde a pessoa seja capaz de interferir criticamente na realidade.

As políticas públicas educacionais apontam estratégias e parâmetros sobre a educação do jovem na escola a fim de que o mesmo adquira uma formação cidadã. As Diretrizes Curriculares Nacionais da Educação Básica (DCN) indicam que o Ensino Médio deve fomentar uma educação integral que contemple o trabalho, a ciência, a tecnologia e a cultura na formação do cidadão e que prepare para o aprofundamento dos estudos, para o exercício da cidadania (BRASIL, 2013). Sob este viés, uma das metas do II Plano Nacional de Educação (PNE) do decênio 2011/2020 aprovada em 2010, indica a importância da viabilidade de recursos tecnológicos digitais no ambiente escolar das escolas no ensino médio para fins pedagógicos (BRASIL, 2010). 
Perante problemas políticos, ambientais e econômicos os quais a educação pode suscitar mudanças significativas de melhorias e soluções cabíveis, nesta pesquisa objetivou-se desempenhar uma análise e discussão de artigos nacionais publicados no período de 2011 à 2018 sobre relatos de experiências de como os professores de Química utilizaram as TDIC em suas aulas, suscitando a Alfabetização Científica dos estudantes no Ensino Médio, aspecto de relevância no processo de escolarização dos mesmos na educação básica.

\section{Metodologia}

Realizou-se uma pesquisa bibliográfica a fim de obter uma percepção das publicações de artigos científicos sobre relatos de experiências de utilização de tecnologias digitais que auxiliaram na formação cidadã dos estudantes no ensino de Química. De acordo com Gil (2008), esta se integra em investigar e analisar cada informação e aspectos relevantes em materiais já elaborados. Priorizou-se por artigos de periódicos científicos em meio eletrônico, pois há uma maior possibilidade destas fontes convergirem com o objetivo.

A fim de auxiliar nesta pesquisa qualitativa, foi utilizado o procedimento técnico de análise do conteúdo Bardin (1977) para a análise dos dados, por se considerar uma ferramenta de análise que possibilita a realização de estudo do objeto pesquisado de forma categorizada, direcionando para os aspectos principais que se almeja investigar.

Realizou-se, no primeiro semestre de 2019, uma pesquisa de artigos publicados sobre tal assunto no portal de periódicos Capes ${ }^{1}$. Foram pesquisadas publicações compreendidas entre os períodos de 2011 a 2018 . O objetivo da escolha deste período é no intuito de obter um maior quantitativo de artigos que abarcam os documentos: PNE 2011-2020 (BRASIL, 2010) e a implementação das DCN (BRASIL, 2013), que procuram promover modificações no cenário educacional brasileiro, ofertando educação de qualidade.

Foram adquiridos 207 (duzentos e sete) artigos. Realizou-se uma leitura exploratória ${ }^{2}$ através de seus resumos para fazer um reconhecimento do material desconhecido. Foram filtrados e selecionados apenas os que apresentavam relatos de experiência de professores de Química que fomentaram o ensino desta disciplina correlacionado com a Alfabetização Científica, auxiliados por tecnologias digitais.

\footnotetext{
${ }^{1}$ www.periodicos.capes.gov.br

2 É uma leitura do material bibliográfico que tem por objetivo verificar em que medida a obra consultada interessa à pesquisa. (GIL, 2008, p.77).
} 
Foram selecionados para análise 18 (dezoito) artigos que obedeciam a estes critérios. No propósito de otimizar esta análise, os artigos foram identificados pela letra (A) seguido de uma numeração crescente. No Quadro 1 encontram-se as informações destes artigos.

Quadro 1 - Informações dos artigos pesquisados

\begin{tabular}{|c|c|c|}
\hline Símbolo & Periódico & Título/Autores/Ano \\
\hline A1 & $\begin{array}{l}\text { Ensino de ciências e } \\
\text { tecnologia em revista }\end{array}$ & $\begin{array}{c}\text { Jogo da radiação: elaboração de um recurso } \\
\text { computacional educativo articulado ao contexto CTSA e } \\
\text { a percepção docente e discente (CHACON, RIBEIRO, } \\
\text { BORGES, 2016) }\end{array}$ \\
\hline $\mathrm{A} 2$ & Química nova na escola & $\begin{array}{l}\text { Nanotecnologia, um tema para o ensino médio } \\
\text { utilizando a abordagem CTSA (REBELLO et. al., 2012) }\end{array}$ \\
\hline A3 & $\begin{array}{l}\text { Revista brasileira de ensino } \\
\text { de C\&T }\end{array}$ & $\begin{array}{l}\text { Uma proposta didática com abordagem CTS para o } \\
\text { estudo dos gases e a cinética química utilizando a } \\
\text { temática da qualidade do ar interior (OLIVEIRA, } \\
\text { GUIMARÃES, LORENZETTI, 2015) }\end{array}$ \\
\hline A4 & Química nova na escola & $\begin{array}{l}\text { Ensino de modelos para o átomo por meio de recursos } \\
\text { multimídia em uma abordagem investigativa (SILVA, } \\
\text { FERREIRA, SILVEIRA, 2014) }\end{array}$ \\
\hline A5 & Revista virtual de química & $\begin{array}{l}\text { Ensino de Química no PROEJA: Uma proposta } \\
\text { integradora das relações entre a sala de aula e um fórum } \\
\text { virtual (SOUZA, PIRES, LINHARES, 2015) }\end{array}$ \\
\hline A6 & $\begin{array}{l}\text { Revista brasileira de ensino } \\
\text { C\&T }\end{array}$ & $\begin{array}{l}\text { Vitamina C: Uma proposta para abordagem de funções } \\
\text { orgânicas no ensino médio (MARTINS et. al., 2015) }\end{array}$ \\
\hline A7 & Química nova na escola & $\begin{array}{l}\text { A utilização de vídeos didáticos nas aulas de Química no } \\
\text { ensino médio para abordagem histórica e } \\
\text { contextualizada do tema vidros (SILVA et. al., 2012) }\end{array}$ \\
\hline A8 & Química nova na escola & $\begin{array}{l}\text { Desenvolvimento e aplicação de webquest para ensino } \\
\text { de Química orgânica: Controle biorracional da lagarta- } \\
\text { do-cartucho de milho (SILVA et. al., 2016) }\end{array}$ \\
\hline A9 & Revista Holos & $\begin{array}{l}\text { Proposta educativa utilizando o jogo rpg maker: } \\
\text { estratégia de conscientização e de aprendizagem da } \\
\text { química ambiental (SOUZA et. al., 2015) }\end{array}$ \\
\hline A10 & Revista principia & $\begin{array}{c}\text { Contextualizando a temática gases no Ensino Médio sob } \\
\text { uma perspectiva dialogada e experimental } \\
\text { (FIGUEIRÊDO et.al., 2015) }\end{array}$ \\
\hline A11 & $\begin{array}{l}\text { Revista novas tecnologias } \\
\text { na educação }\end{array}$ & $\begin{array}{l}\text { A utilização de laboratórios virtuais no Ensino de } \\
\text { química para a educação de jovens e adultos } \\
\text { (FEHLBERG, VARGAS, COSTA, 2016) }\end{array}$ \\
\hline A12 & $\begin{array}{l}\text { Revista debates em ensino } \\
\text { de química }\end{array}$ & $\begin{array}{c}\text { Conscientização social e preservação ambiental: } \\
\text { desenvolvimento de valores em aulas de Química a } \\
\text { partir do tema plásticos (FREITAS, MÜNCHEN, } \\
\text { CALIXTO, 2016) }\end{array}$ \\
\hline A13 & $\begin{array}{l}\text { Revista brasileira de ensino } \\
\text { de química }\end{array}$ & $\begin{array}{l}\text { Disciplina temática de química: espaço para a formação } \\
\text { cidadã dos estudantes do ensino médio (OLIVEIRA et. } \\
\text { al., 2014) }\end{array}$ \\
\hline A14 & $\begin{array}{l}\text { Revista brasileira de ensino } \\
\text { de química }\end{array}$ & $\begin{array}{c}\text { Energia versus poluição atmosférica: uma oficina } \\
\text { temática para o Ensino de Química (WOLLMANN, } \\
\text { BRAIBANTE, 2013) }\end{array}$ \\
\hline
\end{tabular}




\begin{tabular}{|c|c|c|}
\hline A15 & $\begin{array}{c}\text { Revista debates em ensino } \\
\text { de química }\end{array}$ & $\begin{array}{c}\text { Execução de uma proposta didática interdisciplinar } \\
\text { sobre o tema "energia" (ELIAS, VERDEAUX, 2017) }\end{array}$ \\
\hline A16 & $\begin{array}{c}\text { Revista brasileira de ensino } \\
\text { de química }\end{array}$ & $\begin{array}{c}\text { Lixo e sociedade: contextualização por meio de uma } \\
\text { abordagem CTSA no ensino de Química (COSTA } \text { et. } \\
\text { al., 2016) }\end{array}$ \\
\hline A17 & $\begin{array}{c}\text { Revista brasileira de ensino } \\
\text { de química }\end{array}$ & $\begin{array}{c}\text { O debate sobre agrotóxicos na perspectiva de uma } \\
\text { produção narrativa audiovisual realizada por alunos de } \\
\text { uma escola pública (SOUZA, ARROIO, WEBER, 2013) }\end{array}$ \\
\hline A18 & $\begin{array}{c}\text { Revista brasileira de ensino } \\
\text { de química }\end{array}$ & $\begin{array}{c}\text { Os plásticos e seus impactos econômicos e ambientais } \\
\text { no ensino de Química (SILVA, REGIANI, NICOLLI, } \\
\text { 2013) }\end{array}$ \\
\hline
\end{tabular}

Fonte: Elaborado pelos autores em 2019

Para análise dos artigos na etapa seguinte, seguiu-se com uma leitura flutuante. Após essa leitura, no intuito de convergir e responder ao objetivo aqui mencionado, seguiu-se com análise categorizada direcionando para os aspectos principais que se desejou analisar, inferência e interpretação dos mesmos, segundo Bardin (1977). A partir destas etapas, contribuindo para a análise qualitativa, foram estruturadas e utilizadas as categorias seguintes: 1-Recursos digitais e metodologias utilizadas; 2-Temas sócio-científicos tratados para abordagem; 3-Percepções e resultados encontrados.

\section{Resultados}

\subsection{RECURSOS DIGITAIS E METODOLOGIAS UTILIZADAS}

Realizou-se nesta etapa uma análise dos artigos para apresentar os recursos metodológicos e quais as tecnologias digitais utilizadas pelos professores para promover a alfabetização científica de modo que seus objetivos fossem alcançados em suas atividades.

Foram apresentadas nestas metodologias as propriedades de iniciarem tais atividades com indagações sobre problemas sociais do cotidiano e que possuem ligação com conteúdos de Química, no propósito de suscitar a reflexão dos estudantes. Os problemas sociais foram discutidos na categoria seguinte "Temas sócio-científicos tratados para abordagem". Os artigos A1, A3, A12, A16, A17 trabalharam com estes questionamentos introduzidos ao recurso de tecnologias digitais. Por sua vez, os artigos A2, A5, A10, A13, A15, A18 utilizaram tecnologias digitais vinculados a atividades práticas em laboratório. Os artigos A6 e A11, além dos recursos digitais e atividades práticas em laboratório, incorporaram a estas atividades questionários avaliativos para os educandos. No artigo A7 foi utilizada tecnologia digital incorporado à história da ciência, e no A12 desenvolveu-se uma atividade sobre júri simulado. Por sua vez, os artigos A4, A8, A9 e A14 desenvolveram estas atividades a partir de tecnologias digitais 
correlacionadas a metodologias ativas como Ensino por Investigação, Metodologia da Problematização e Estudo de Caso.

O artigo A4 trabalhou com Ensino por Investigação. Os artigos A8 e A9 trabalharam com Estudo de Caso sobre o controle de pragas em plantações e impactos ambientais sucessivamente. Por sua vez o artigo A14 trabalhou com Metodologia da Problematização a respeito de energia e poluição atmosférica.

Estes últimos artigos evidenciaram que os professores de Química procuraram trabalhar com metodologias diferentes, posto que aplicaram metodologias ativas em suas aulas, demonstrando que estes profissionais procuram acompanhar as exigências feitas em sua profissão, e fomentaram uma didática diferente possibilitando a construção cognitiva dos estudantes, uma vez que as metodologias ativas

\section{Baseiam-se em formas de desenvolver o processo de aprender, utilizando experiências reais ou simuladas, visando às condições de solucionar, com sucesso, desafios advindos das atividades essenciais da prática social, em diferentes contextos (BERBEL, 2011, p. 29).}

Percebe-se que foram desempenhadas atividades que fomentaram a formação cognitiva, crítica e reflexiva dos educandos, o que sugere a ideia de que estes profissionais promoveram aulas com cenário diferente das aulas onde ocorre apenas a transmissão de conteúdos do professor para o aluno, corroborando com o que é apresentado por Chassot (2003) e Libâneo (2011) a respeito da importância de práticas didáticas do docente para ajudar os estudantes a potencializarem suas capacidades cognitivas e formação social.

Sobre as tecnologias digitais utilizadas nestas atividades, as mesmas foram apresentadas no Quadro 2.

Quadro 2 - Tecnologias digitais utilizadas

\begin{tabular}{|c|c|}
\hline Artigos & Tecnologias digitais \\
\hline A1, A9 & Jogo virtual \\
\hline $\begin{array}{c}\text { A2, A6, A7, A10, A11, A12, A13 } \\
\text { A14, A15, A16, A17, A18 }\end{array}$ & Produção de vídeos \\
\hline A3 & Vídeos/publicações de endereços eletrônicos \\
\hline A4 & Vídeos/simulações do Phet \\
\hline A5 & Espaço virtual de aprendizagem (chat e fórum) \\
\hline A8 & Endereço eletrônico Webquest \\
\hline
\end{tabular}

Fonte: Elaborado pelos autores em 2019 
Observa-se algumas opções de TDIC utilizadas nos artigos. Há uma predominância na produção e utilização de vídeos como recursos didáticos, o que sugere que os vídeos são recursos mais disponíveis aos professores, no ambiente escolar. Fantini e Mateus (2015, p.68) indicam que "vídeos podem ampliar o número de situações observadas e levadas em consideração pelos alunos no tratamento de um tema.[...] Outra vantagem é que a exibição dos vídeos pode ser repetida várias vezes".

Cabe salientar, a importância de as escolas ofertarem uma estrutura apropriada com tecnologias digitais e acesso a internet em seus espaços, de modo a possibilitar a promoção do trabalho docente de forma satisfatória, para que não ocorra imprevistos como relatado no artigo A15

\begin{abstract}
Em relação aos recursos audiovisuais acreditamos que a nota relativamente baixa atribuída pela média da turma tenha relação com a lentidão da conexão à internet disponibilizada pela escola. Muitas vezes surgia durante a discussão de um subtema a necessidade de apresentar vídeos e outros recursos disponibilizados online, necessidade que às vezes esbarrava em problemas de conexão (ELIAS e VERDEAUX, 2017, p.208).
\end{abstract}

Fica caracterizado pelo relato apresentado que ainda há a carência de oferta de conexão com a internet em algumas instituições escolares, como nesta instituição, por exemplo. O que sugere a necessidade de a estratégia 3.11 do PNE 2011-2020 (BRASIL, 2010) sobre "universalizar o acesso à rede mundial de computadores em banda larga de alta velocidade" ser atendida até o fim de sua vigência.

É possível salientar ainda dentro deste contexto a utilização do jogo virtual por A1. Este artigo indica o subsídio de financiamento pelo Ministério da Educação e Ministério da Ciência, Tecnologia, Inovações (MCTI), para a elaboração do jogo virtual. O que sugere que este recurso não é utilizado com maior frequência pelos professores devido às dificuldades financeiras e estruturais que algumas instituições escolares apresentam. No caso de os professores não possuírem recurso ou formação em informática para o desenvolvimento de jogos, é possível adquirir nos repositórios digitais jogos prontos que podem ser utilizados em suas aulas para fins didáticos como salienta (LEITE, 2015).

Os autores trabalharam com metodologias e estratégias didáticas diversas para atender aos seus objetivos. Os artigos A4, A8, A9, A14 utilizaram metodologia da problematização, ensino por investigação e estudo de caso. O A12 trabalhou com Júri simulado, e os artigos A2, A3, A5, A6, A10, A11, A13, A15, A18 experimentação.

O Júri simulado é uma estratégia didática que suscita o aprendizado além de habilidades argumentativas dos estudantes, aspectos relevantes que precisam ser desenvolvidos ao se 
promover a formação cidadã. Os autores do artigo A12 utilizaram esta estratégia fomentando a tomada de decisão dos estudantes diante do problema apresentado sobre proibição das sacolas plásticas. Vieira, Melo e Bernardo (2014) apontam que nesta forma de organização de atividade

\begin{abstract}
As pessoas engajadas devem ser separadas em grupos a favor, contra e juízes, em uma discussão sobre um determinado tópico ou questão; ou seja, em júris simulados, há atacantes, defensores e juízes de uma questão em discussão. Nessas atividades, o professor pode assumir uma dessas funções ou papéis ou atuar como mediador. Ao atuar como mediador, o professor organiza e estrutura as contribuições dos grupos. Assim, em atividades de júri simulado, os estudantes podem assumir diferentes papéis enunciativos, tais como defensor, oponente ou juiz dos argumentos produzidos (VIEIRA, MELO e BERNARDO, 2014, p. 205).
\end{abstract}

Os demais artigos utilizaram aulas expositivas para colaborar em suas propostas didáticas trabalhadas. Vale destacar que a maioria dos artigos utilizou como uma das etapas do roteiro metodológico, aulas práticas experimentais, corroborando com a proposta de Machado e Mortimer (2007) que destacam a necessidade de a proposta didática de Química ser articulada sob três aspectos, para promover o entendimento do estudante, que muitas vezes considera esta disciplina de difícil entendimento por ser abstrata. As aulas práticas experimentais podem ser introduzidas no aspecto fenomenológico, que segundo estes autores são configurados aos fenômenos desenvolvidos nas aulas que podem ser concretos e visíveis.

Estes autores possivelmente utilizaram este recurso, pois as aulas experimentais são alternativas didáticas que oportunizam a aproximação do estudante com o conteúdo estudado e, segundo Santos e Porto $(2014$, p.321) "as práticas experimentais representam atividades envolventes e instigadoras, sendo capazes de promover uma participação efetiva do aluno, estimulando assim, sua busca pelo conhecimento". Consideradas como estratégias alternativas utilizadas pelos professores de Química, as aulas experimentais tradicionais auxiliam os estudantes no entendimento de conteúdos curriculares desta disciplina abordados em sala de aula.

\title{
3.2. TEMAS SÓCIO-CIENTÍFICOS TRATADOS PARA ABORDAGEM
}

O professor ao promover o ensino de Química convergindo com a Alfabetização Científica, precisa estruturar os conteúdos de forma a oportunizar a relação entre ambos e as aplicações de Química no contexto social. Sob este viés Chassot (2003) e Freire (1987) apontam a responsabilidade de o professor subsidiar a transformação nos educandos em cidadãos mais críticos a partir de reflexões fomentadas nas aulas pelos temas sócio-científicos.

Realizou-se nesta categoria uma investigação para o entendimento de como as atividades proporcionaram a formação crítica dos jovens. Neste cenário deve haver a 
contextualização entre os conteúdos curriculares e temas conflitantes da sociedade, possibilitando o momento de reflexão do estudante, tomada de decisão e resolução de problemas sobre os temas. Silva $(2007$, p.14) indica que "uma maneira muito simples de entender a abordagem temática é partir de um tema, que se relaciona a uma situação-problema, como um pretexto para o desenvolvimento dos conteúdos químicos".

Estes temas devem ser organizados de maneira a possibilitar que o estudante acompanhe as atividades que serão ofertadas pelo professor. Muenchen e Delizoicov (2014) destacam os três momentos pedagógicos que devem existir quando o professor realiza uma atividade em sala de aula com o estudante, no intuito de fomentar a formação cidadã, que são problematização inicial, organização do conhecimento, aplicação do conhecimento. Segundo Muenchen e Delizoicov (2012, 2014), os conteúdos curriculares são estruturados a partir de temas originados da realidade dos estudantes, oportunizando sua melhor compreensão sobre os temas e conteúdos curriculares.

Na problematização inicial o educador expõe situações do cotidiano dos estudantes por meio de questionamentos que convergem com os temas sociais, permitindo a discussão e reflexão do educando por meio de seus conhecimentos prévios sobre o tema discutido e estudado. Na etapa seguinte organiza-se a maneira que serão trabalhados e contextualizados os conteúdos curriculares que possibilitarão o entendimento dos estudantes, proporcionando suas concepções sobre outras possibilidades de explicação a respeito da problemática apresentada na etapa anterior. Na última etapa configura-se o momento em que os educandos utilizam os conhecimentos adquiridos para analisar e interpretar o cenário previamente apresentado pelo professor. Os temas geradores e sociais utilizados nos artigos pelos autores estão apresentados no Quadro 3.

Quadro 3 - Temas geradores e sociais utilizados para abordagem em Química

\begin{tabular}{|c|c|c|}
\hline Artigos & Temas geradores & Temas sociais \\
\hline A1 & $\begin{array}{c}\text { Entendimento da sociedade sobre a } \\
\text { radiação }\end{array}$ & \\
\hline A2 & $\begin{array}{c}\text { Nanotecnologia na sociedade e suas } \\
\text { implicações }\end{array}$ & \\
\hline A3 & Gases poluentes e aspectos políticos & $\begin{array}{c}\text { Entendimento da sociedade sobre } \\
\text { constituição da matéria }\end{array}$ \\
\hline A4 & & Pilhas e baterias \\
\hline A5 & & Vitamina C e benefícios à saúde \\
\hline A6 & & \\
\hline
\end{tabular}




\begin{tabular}{|c|c|c|}
\hline A7 & & Utilização do vidro e reciclagem \\
\hline A8 & Prática agrícola sustentável & \\
\hline A9 & $\begin{array}{l}\text { Chuva ácida; efeito estufa; agrotóxicos; } \\
\text { metais pesados }\end{array}$ & \\
\hline A10 & & Gases e pressão no espaço doméstico \\
\hline A11 & & Consumo consciente de álcool \\
\hline A12 & Plásticos e consumo na sociedade & \\
\hline A13 & & $\begin{array}{l}\text { Propriedades físicas e químicas do gelo; a } \\
\text { química do cabelo elétrico; corrosão e } \\
\text { maresia; mudança de cor de óculos } \\
\text { fotocromáticos; química dos refrigerantes; } \\
\text { propriedades da água do mar; polímeros; } \\
\text { petróleo como ouro negro; química do } \\
\text { bafômetro; fogos de artifício }\end{array}$ \\
\hline A14 & Energia e poluição atmosférica & \\
\hline A15 & Energia em impactos ambientais & \\
\hline A16 & Geração de lixo e impactos ambientais & \\
\hline A17 & Agrotóxicos & \\
\hline A18 & Plásticos e impacto ambiental & \\
\hline
\end{tabular}

Fonte: Elaborado pelos autores em 2019

Os artigos procuraram trabalhar com temáticas amplas de interesse da sociedade. Para uma melhor compreensão do desenvolvimento da contextualização entre Química e os temas geradores e sociais, foram utilizadas as etapas "Problematização inicial" e "Aplicação do conhecimento", propostas por Muenchen e Delizoicov (2014), a fim de realizar uma atividade em sala de aula que fomente a formação cidadã. Estas informações dos artigos são apresentadas no Quadro 4.

Quadro 4 - Formas de contextualização trabalhadas

\begin{tabular}{|c|c|c|}
\hline Artigos & Problematização inicial & Aplicação do conhecimento \\
\hline A1 & $\begin{array}{c}\text { Discussão sobre o entendimento } \\
\text { equivocado da radiação na sociedade }\end{array}$ & $\begin{array}{c}\text { No jogo são apresentados situações e } \\
\text { perguntas para a reflexão do aluno }\end{array}$ \\
\hline A2 & $\begin{array}{c}\text { Discussão sobre a forma de obtenção de } \\
\text { nanopartícula }\end{array}$ & $\begin{array}{c}\text { Debates sobre as aplicações e benefícios da } \\
\text { nanotecnologia }\end{array}$ \\
\hline A3 & $\begin{array}{c}\text { Articulação dos perigos da poluição do ar } \\
\text { em prédios e transportes públicos }\end{array}$ & $\begin{array}{c}\text { Debates contextualizados com as aulas } \\
\text { anteriores sobre o efeito do catalisador para } \\
\text { acelerar a reação de decomposição }\end{array}$ \\
\hline A4 & $\begin{array}{c}\text { Discussão sobre as primeiras ideias de } \\
\text { filósofos sobre a constituição da matéria }\end{array}$ & $\begin{array}{c}\text { Aplicação de perguntas (questionário) } \\
\text { sobre as atividades anteriormente } \\
\text { desempenhadas }\end{array}$ \\
\hline
\end{tabular}




\begin{tabular}{|c|c|c|}
\hline A5 & $\begin{array}{c}\text { Experimentos com materiais alternativos e } \\
\text { perguntas relacionadas a estes } \\
\text { experimentos sobre os fenômenos } \\
\text { observados }\end{array}$ & $\begin{array}{l}\text { Experimentos diferentes do inicial } \\
\text { favorecendo a aplicação dos } \\
\text { conhecimentos adquiridos anteriormente }\end{array}$ \\
\hline A6 & $\begin{array}{l}\text { Apresentação de questionamentos } \\
\text { relacionados a temática da vitamina C }\end{array}$ & $\begin{array}{c}\text { Realização de um experimento } \\
\text { problematizado relacionado à temática e } \\
\text { aplicação de questionário sobre os temas } \\
\text { trabalhados }\end{array}$ \\
\hline A7 & $\begin{array}{c}\text { Abordagem histórica da produção do vidro, } \\
\text { aplicações e reciclagem }\end{array}$ & $\begin{array}{c}\text { Aplicação de questionário que } \\
\text { possibilitasse a utilização dos } \\
\text { conhecimentos adquiridos para responder o } \\
\text { mesmo }\end{array}$ \\
\hline A8 & $\begin{array}{l}\text { Aplicação de transposição didática sobre o } \\
\text { tema tratado e a relação com o conteúdo } \\
\text { curricular de Química }\end{array}$ & $\begin{array}{l}\text { Resolução e apresentação do estudo de } \\
\text { caso pelos alunos sobre o tema trabalhado }\end{array}$ \\
\hline A9 & $\begin{array}{c}\text { A proposta didática do jogo aborda } \\
\text { situações diversas dos impactos ambientais } \\
\text { ocasionados pela utilização de produtos } \\
\text { químicos }\end{array}$ & $\begin{array}{l}\text { Aplicação de questionário com perguntas } \\
\text { relacionadas com os temas tratados }\end{array}$ \\
\hline A10 & $\begin{array}{l}\text { Introdução do tema de forma } \\
\text { contextualizada sobre como este estava } \\
\text { inserido no cotidiano do educando }\end{array}$ & $\begin{array}{c}\text { Diálogo sobre as atividades realizadas para } \\
\text { fomentar o raciocínio e a interação entre a } \\
\text { turma }\end{array}$ \\
\hline A11 & $\begin{array}{l}\text { Aplicação de questionário sobre os } \\
\text { conhecimentos prévios de destilação e a } \\
\text { relação com o consumo de álcool }\end{array}$ & $\begin{array}{c}\text { Aplicação de outro questionário sobre os } \\
\text { temas tratados e os conhecimentos } \\
\text { adquiridos }\end{array}$ \\
\hline A12 & $\begin{array}{l}\text { Apresentação do vídeo sobre o tema } \\
\text { tratado e questionário sobre os } \\
\text { conhecimentos prévios do educandos }\end{array}$ & $\begin{array}{c}\text { Aplicação de outro questionário sobre os } \\
\text { conhecimentos obtidos pelos estudantes } \\
\text { após as atividades }\end{array}$ \\
\hline A13 & $\begin{array}{l}\text { Apresentação da situação problema com } \\
\text { discussões sobre o tema tratado }\end{array}$ & $\begin{array}{l}\text { Aplicação de prova, seminário, debate, } \\
\text { relatórios após experimentação }\end{array}$ \\
\hline A14 & $\begin{array}{l}\text { Discussão inicial sobre a poluição } \\
\text { atmosférica e a relação com o processo de } \\
\text { combustão realizado nas indústrias }\end{array}$ & $\begin{array}{l}\text { Atividade em grupo que fomentou a } \\
\text { reflexão dos estudantes a apresentação de } \\
\text { propostas para minimizar o problema } \\
\text { previamente discutido }\end{array}$ \\
\hline A15 & $\begin{array}{c}\text { Desenvolvimento de discussões sobre o } \\
\text { tema tratado e a relação com questões do } \\
\text { cotidiano }\end{array}$ & $\begin{array}{c}\text { Realização de experimentos os quais os } \\
\text { estudantes puderam aplicar seus } \\
\text { conhecimentos obtidos }\end{array}$ \\
\hline A16 & $\begin{array}{l}\text { Apresentação inicial da temática e } \\
\text { perguntas que fomentassem a reflexão dos } \\
\text { educandos }\end{array}$ & $\begin{array}{l}\text { Aplicação de questionário sobre os } \\
\text { conhecimentos adquiridos e proposta de } \\
\text { elaboração de objetos com material } \\
\text { reciclado para exposição em uma feira }\end{array}$ \\
\hline A17 & $\begin{array}{c}\text { Aplicação de perguntas sobre } \\
\text { conhecimentos prévios sobre o tema e } \\
\text { discussão do mesmo }\end{array}$ & $\begin{array}{c}\text { Debate sobre os conhecimentos obtidos e } \\
\text { produção de vídeo pelos alunos sobre o } \\
\text { tema }\end{array}$ \\
\hline
\end{tabular}




\begin{tabular}{|c|c|c|}
\hline A18 & $\begin{array}{c}\text { Introdução do tema e aplicação de } \\
\text { perguntas para os estudantes apresentarem } \\
\text { seus conhecimentos prévios }\end{array}$ & $\begin{array}{c}\text { Elaboração de um texto dissertativo pelos } \\
\text { estudantes com propostas de reciclagem do } \\
\text { plástico }\end{array}$ \\
\hline
\end{tabular}

Fonte: Elaborado pelos autores em 2019

O artigo A13 relata o desenvolvimento de uma disciplina que teve a duração de nove meses. Por este motivo, foram trabalhados mais de um tema para discussão, bem como atividades diversas para fomentar a aplicação dos conhecimentos dos estudantes ao fim de cada aula.

Com exceção dos artigos A4, A5, A6, A10 e A11 que empregaram como temas respectivamente: entendimento da sociedade sobre constituição da matéria; pilhas e baterias; vitamina C e saúde; utilização de gases; consumo de bebida alcoólica, os demais artigos trabalharam temas associados a questões ambientais.

O artigo A11, por exemplo, trabalhou com a questão do consumo de bebida alcoólica por meio do conteúdo de destilação, promovendo a conscientização da turma de Educação de Jovens e Adultos (EJA) sobre a relevância do consumo de bebida alcoólica de forma consciente.

No artigo A8, os autores procuraram trabalhar com a temática da utilização excessiva de agrotóxicos nas áreas agrícolas para combater pragas que atingem as plantações, porém ocasionam problemas de saúde nos trabalhadores rurais e impactos ambientais. Os autores trabalharam com estudo de caso, e os estudantes deveriam apresentar soluções para tal problema.

As formas de geração de energia, e os impactos ambientais que estes processos ocasionam foi outra questão ambiental tratada nos artigos. Os autores no artigo A15 procuraram despertar a reflexão dos educandos sobre fontes alternativas de energia, fomentando nos mesmos a compreensão de que são sujeitos transformadores de realidades na sociedade.

Foram discutidos ainda a questão de consumo demasiado de produtos variados, que se transformam em lixo posteriormente, e a sociedade por sua vez ainda não assumiu como prática comum a reciclagem, fomentando em contrapartida problemas socioambientais. No artigo A12 esta questão foi contextualizada com a produção e consumo de plásticos como se observa

\footnotetext{
Pensou-se num tema que possibilitasse estabelecer relações entre aspectos científicos e tecnológicos, além disso, deveria ser atual e apresentar um significado social e questões controversas. Desta forma, optou-se pelo tema plásticos, por apresentar os parâmetros estabelecidos, e ser de vasta utilização no dia a dia de toda sociedade, de tal forma que é difícil contabilizar a quantidade de materiais plásticos que se tem acesso (FREITAS, MÜNCHEN e CALIXTO, 2016, p. 58).
}

$\mathrm{O}$ artigo A2 relata os problemas acarretados pela influência da tecnologia na sociedade, indicando os benefícios e malefícios na sociedade da produção de nanotecnologia. Os autores 
suscitaram a reflexão dos estudantes sobre a relevância do conhecimento e entendimento deste tema relacionado a questões tecnológicas, retratando a necessidade de compreensão da relação que a sociedade possui com a tecnologia e aspectos positivos e negativos desta relação.

Esta proposta corrobora o que Krasilchik e Marandino (2004) sinalizam sobre a relevância de uma sociedade crítica e reflexiva que não seja excluída de conhecimentos sobre os fatores conectados à utilização da tecnologia na contemporaneidade.

Depreende-se que os autores suscitaram a percepção crítico social dos educandos por meio de temas variados, além de atividades que oportunizaram a reflexão destes temas, e entendimento de que mudanças positivas na sociedade são acarretadas por sujeitos que sejam atuantes e participativos nesta sociedade, como é proposto pelo DCN (BRASIL, 2013).

\subsection{PercepÇões e Resultados encontrados}

Observou-se após leitura dos artigos, a oportunidade de realização de aulas de Química nas turmas de ensino médio, sob o viés da alfabetização científica, com a aplicação de tecnologias digitais fomentando esta interface de conhecimentos. Todos os autores dos artigos analisados declararam a receptividade dos educandos em relação à utilização de tais tecnologias, corroborando a ideia de Guerra (2015), Leite (2015) e Silva (2012), a respeito da aptidão e receptividade dos jovens atualmente de manipular as TDIC, e com o DCN (BRASIL, 2013) que declara a viabilidade das tecnologias fomentarem o desenvolvimento cognitivo do educando no espaço escolar.

Além da receptividade e participação com as atividades desenvolvidas, os artigos declararam que os educandos tiveram maior compreensão dos conteúdos de Química, desenvolvimento de suas reflexões, tomada de opiniões sobre os temas sociais trabalhados, e demonstraram interesse de apontar sugestões e/ou soluções para estes problemas sociais. Estas características convergem com a proposta de uma educação pautada na formação cidadã segundo (CHASSOT, 2003; FREIRE, 1987; KRASILCHIK e MARANDINO, 2004).

As atividades realizadas em grupo possibilitaram elucubrações dos estudantes bem como oportunidade de debater os temas trabalhados nestes artigos. Vale salientar a relevância da utilização de temas do cotidiano para fomentar ganhos cognitivos aos jovens, como indicam Muenchen e Delizoicov $(2012$, 2014) a respeito dos momentos pedagógicos, e as elaborações de propostas didáticas que promovam estas interações, como as metodologias ativas descritas por Berbel (2011). 
Os artigos A4 e A18 por sua vez, declararam que ao longo da realização das atividades, os estudantes apresentaram dificuldades e dúvidas com os conteúdos trabalhados. Tal fato demandou dos professores maior atenção para ajudar os estudantes no entendimento dos conteúdos, havendo a necessidade de os professores utilizarem recursos como perguntas que incentivassem a reflexão sobre o conteúdo de Química e o tema social.

Isto demonstra a relevância de o professor adquirir uma formação que lhe propicie estar preparado para sanar estes e outros problemas, como Carvalho e Perez (2009) e Libâneo (2011) salientam sobre a questão da formação de professores que os permita um preparo para trabalhar com situações distintas, sem perder sua importância profissional.

\section{CONSIDERAÇÕES FINAIS}

A incorporação no espaço escolar de TDIC para atender os documentos de políticas públicas, sem a necessária qualificação dos professores para utilizarem estes recursos, não favorece para as importantes transformações que precisam ocorrer na educação brasileira. Cabe salientar que a estruturação de saberes convergindo com a utilização de TDIC, deve cooperar para que seja possível a concretização de uma aula produtiva suscitando a formação crítica e reflexiva do estudante, além da cognitiva.

A respeito dos recursos digitais utilizados, os autores dos artigos mesmo evidenciando que estes dispositivos foram incorporados nas atividades didáticas, ainda demonstram limitações de utilização sobre a variedade de opções, que são muitas atualmente. Corroborando a relevância de os cursos de formação de professores promoverem a estes, conhecimento e utilização de recursos digitais diversos.

Sobre os temas sócio-científicos utilizados para promover a Alfabetização Científica dos estudantes, observou-se a abordagem de questões ambientais com contextualizações diferentes. Os autores procuraram motivar a reflexão dos estudantes sobre fontes alternativas de energia, suscitando suas concepções de que são sujeitos transformadores de realidades da sociedade.

Com a análise das informações adquiridas nos artigos científicos nacionais, esta pesquisa contribuiu para a discussão e reflexão sobre a importância de os professores adquirirem maior autonomia na utilização de TDIC nos espaços escolares para saber como e quando utilizar estes dispositivos de maneira produtiva. Assim como a relevância da formação cidadã contextualizada no ensino de Química, transcorrer de forma mais eficiente. 
Perante muitos obstáculos que o professor de Química precisa confrontar em sua prática profissional, fica a elucubração nesta pesquisa sobre seu espaço e seu papel na educação brasileira, e a relevância de sua constante (trans)formação, acompanhando mudanças de contexto político, por exemplo.

Pelo fato desta análise ter se configurado com um estudo de artigos científicos dentro de um período de sete anos, entende-se que outros trabalhos podem ser desenvolvidos de maneira a ampliar os resultados adquiridos nesta pesquisa, bem como na relação com outros trabalhos científicos como dissertações e teses para o mesmo período.

\section{REFERÊNCIAS}

BARANAUSKAS, Maria Cecília Calani; VALENTE, José Armando. Editorial. Tecnologias, Sociedade e Conhecimento, vol.1, $\mathrm{n}^{\mathrm{o}} 1, \mathrm{p} .1-5,2013$.

BARDIN, Laurence. Análise de conteúdo. 1ª edição. São Paulo: Edições 70, 1977.

BERBEL, Neusi Aparecida Navas. As metodologias ativas e a promoção da autonomia de estudantes. Semina: Ciências sociais e humanas, Londrina, vol 32, nº 1, p. 25- 40, 2011.

BRASIL. Plano Nacional de Educação. Estabelece o Plano Nacional de Educação - PNE para o decênio 2011-2020, e dá outras providências. Brasília, DF, 2010. Acesso em: 02 mai. 2019.

BRASIL. Diretrizes Curriculares Nacionais Gerais da Educação Básica. Ministério da Educação do Brasil. Brasília: DF, 2013. Acesso em: 02 mai. 2019.

CARVALHO, Ana Maria Pessoa de; PÉREZ, Daniel Gil. Formação de professores de Ciências. 9a edição. São Paulo: Cortez, Vol. 26, 2009.

CHACON, Eluzir Pedrazzi; RIBEIRO, Carlos Magno Rocha; BORGES, Marcia Narcizo. Jogo da Radiação: elaboração de um software educativo articulado ao contexto CTSA e a percepção docente e discente. Ensino de ciência e tecnologia em revista. RS: v.6, no 1, p. 114, 2016. Disponível em:<

http://srvapp2s.urisan.tche.br/seer/index.php/encitec/search/search>. Acesso em: 02 mai. 2019.

CHASSOT, Attico. Alfabetização científica, questões e desafios para a educação. $3^{\text {a }}$ edição. Ijuí-RS: editora Unijuí, 2003.

COSTA, Maria Aparecida da.; VASCONCELOS, Thais Mateus; OLIVEIRA, Yuri Alves; FIELDS, Karla Amancio Pinto; SANTOS, Renato Gomes. Lixo e Sociedade: contextualização por meio de uma abordagem CTSA no Ensino de Química. Revista brasileira de ensino de química, v. 11, n², p.51-62, 2016. Disponível em:< http://e.issuu.com/embed.html\#2581046/50933991>. Acesso em: 02 mai. 2019.

ELIAS, Juliano de Almeida; VERDEAUX, Maria de Fátima da Silva. Execução de uma proposta didática interdisciplinar sobre o tema Energia. Revista debates em ensino de 
química, v. 3, nº2, 2017. Disponível em:< http://www.journals.ufrpe.br/index.php/REDEQUIM/article/view/1622/1489>. Acesso em: 02 mai. 2019.

FANTINI, Leandro Henrique; MATEUS, Alfredo Luis. Ciência na tela, vídeos em sala de aula. In: MATEUS, Alfredo Luis (org.). Ensino de química mediado pelas TICs. Belo Horizonte: editora UFMG, 2015, p. 67-95.

FEHLBERG, Eduarda; VARGA, Graciel; COSTA, Luciano Andreatta da. A utilização de laboratórios virtuais no ensino de química para a educação de jovens e adultos. Revista novas tecnologias na educação, v.14, no², 2016. Disponível em:〈http://seer.ufrgs.br/index.php/renote/article/view/70649>. Acesso em: 02 mai. 2019.

FIGUEIRÊDO, Alessandra Marcone Tavares Alves de; NASCIMENTO, Mayzza Márcia Araújo do; LIMA, Luís Victor dos Santos; SALES, Flávia Rhuana Pereira; ARAÚJO, Rafael de Carvalho; SOUZA, Niely Silva de. Contextualizando a temática gases no Ensino Médio sob uma perspectiva dialogada e experimental, Revista principia, $n^{\circ} 27$, p.81-88, 2015. Disponível em: 〈http://periodicos.ifpb.edu.br/index.php/principia/article/viewFile/534/316〉. Acesso em: 02 mai. 2019.

FREIRE, Paulo. Pedagogia do oprimido. $17^{\mathrm{a}}$ edição. RJ: editora Paz e terra, 1987.

FREITAS, Wélica Patrícia Souza de; MÜNCHEN, Sinara; CALIXTO, Vivian S. Conscientização social preservação ambiental: desenvolvimento de valores em aulas de química partir do tema plásticos. Revista debates em ensino de química, v. 2, n², p.56-69, 2016. Disponível em:<http://www.journals.ufrpe.br/index.php/REDEQUIM/article/view/1315>. Acesso em: 02 mai. 2019.

GIL, Antonio Carlos. Como elaborar projetos de pesquisa. $5^{\text {a }}$ edição. São Paulo: editora Atlas, 2008.

GUERRA, Oldênia Fonseca. Tecnologias de informação e comunicação e a interface com a educação profissional: da formação às práticas pedagógicas. 2015. 234p. Tese de doutorado do Programa de Pós-Graduação em Educação da Universidade Federal do Rio de Janeiro, Rio de Janeiro, 2015.

KRASILCHIC, Myriam; MARANDINO, Martha. Ensino de Ciências e cidadania. $1^{\text {a }}$ edição. São Paulo: editora Moderna, 2004.

LEITE, Bruno Silva. Tecnologias no ensino de química, teoria e prática na formação docente. $1^{\text {a }}$ edição. Editora Appris, 2015.

LIBÂNEO, José Carlos. Adeus professor, adeus professora? Novas exigências educacionais e profissão docente. $13^{\mathrm{a}}$ edição. São Paulo: editora Cortez, volume 2, 2011.

MACHADO, Andréa Horta; MORTIMER, Eduardo Fleury. Química para o ensino médio: Fundamentos, pressupostos e o fazer cotidiano. In: ZANON, Lenir Basso; MALDANER, Otavio Aloisio (org.). Fundamentos e propostas de ensino de química para a educação básica no Brasil. Ijuí-RS: editora Unijuí, 2007. 
MARTINS, Jéssica Guerreiro; MACHADO, Bruno Rafael; BARON, Alessandra Machado; TONIN, Lilian Tatiani Dusman. Vitamina C: uma proposta para Abordagem de Funções Orgânicas no ensino médio. Revista brasileira de ensino de C\&T, v.8, nº2, 2015.

Disponível em: $<$ https://periodicos.utfpr.edu.br/rbect/article/view/2988 > . Acesso em: 02 mai. 2019.

MUENCHEN, Cristiane; DELIZOICOV, Demétrio. Os três momentos pedagógicos e o contexto de produção do livro "Física". Ciência educação, vol. 20, n³, p. 617-638, 2014.

MUENCHEN, Cristiane; DELIZOICOV, Demétrio. A construção de um processo didáticopedagógico dialógico: aspectos epistemológicos. Revista Ensaio, vol. 14, n³, p. 199-215, 2012 .

NASCIMENTO, Fabrício do; FERNANDES, Hylio Laganá; MENDONÇA, Viviane Melo de. O ensino de ciências no Brasil: história, formação de professores e desafios atuais.

Universidade Federal de São Carlos - UFSCar, Revista HISTEDBR On-line, n.39, p. 225249, set.2010.

OLIVEIRA, Leandro Severino de; FALCÃO, Nathália Kellyne Silva Marinho; SANTOS, Vanúbia Pontes dos; JUNIOR, Umberto Gomes da Silva; FERREIRA, Jailson Machado. Disciplina Temática de Química: espaço para a formação cidadã dos estudantes do ensino médio. Revista brasileira de ensino de química, v. 9, n² 2, 2014. Disponível em:〈http://rebeq.revistascientificas.com.br/edicoes.php?id=91>. Acesso em: 02 mai. 2019.

OLIVEIRA, Silvaney de; GUIMARÃES, Orliney Maciel; LORENZETTI, Leonir. Uma proposta didática com abordagem CTS para o estudo dos gases e cinética química utilizando a temática da qualidade do ar interior. Revista brasileira de ensino de ciência e tecnologia, v.8, nº4, 2015. Disponível em:<https://periodicos.utfpr.edu.br/rbect/article/view/1823>. Acesso em: 02 mai. 2019.

PRETTO, Nelson de Luca; RICCIO, Nicia Cristina Rocha. A formação continuada de professores universitários e as tecnologias digitais. Educar, Curitiba, editora UFPR, $\mathrm{n}^{\mathbf{0}} 37$, p. 153-169, 2010.

REBELLO, Gabriel Antonio Fontes; ARGYROS, Mécia de Matos; LEITE, Wallace Leonardo Lopes; SANTOS, Mayke Machado; BARROS, José Celestino; SANTOS, Paula Macedo Lessa dos; SILVA, Joaquim Fernando Mendes da. Nanotecnologia, um tema para o ensino médio utilizando a abordagem CTSA. Química nova na escola, v. 34, nº 1, p.3-9, 2012. Disponível em: $<$ http://qnesc.sbq.org.br/online/qnesc34_1/02-QS-7910.pdf?agreq $=$ Nanotecnologia, $\% 20 \mathrm{um} \% 20$ tema $\% 20$ para $\% 20 \mathrm{o} \% 20 \mathrm{ensino} \% 20 \mathrm{~m} \% \mathrm{C} 3 \%$ A9dio \%20\&agrep=qnesc $>$. Acesso em: 02 mai. 2019.

SANTOS, José Ricardo Almeida dos; NASCIMENTO, Gabriel Rodrigues do; MACIEL, Paula Priscila Rocha; CORDEIRO, José Pedro. Utilização dos recursos da internet para o ensino de ciências na casa da física. 2007.

SANTOS, A. O.; SILVA, R. P.; ANDRADE, D.; LIMA, J. P. M. Dificuldades e motivações de aprendizagem em Química de alunos do ensino médio investigadas em ações do (PIBID/UFS/Química). Scientia Plena, v. 9, n. 7, p. 1 - 6, 2013. 
SANTOS, Ludmylla Ribeiro dos; PORTO, Maria das Graças Cleophas. Proposta experimental para o ensino de Química: Utilizando indicador natural de $\mathrm{pH}$ obtido a partir da biodiversidade da região da serra da Capivara. Extramuros revista de extensão da Univasf, vol 3, no $1,2014$.

SILVA, Dayse Pereira da. Temas geradores no ensino de química. In: Oficinas temáticas no ensino público Formação continuada de professores. Grupo de pesquisa em educação química, USP-SP, 2007, p. 13-22.

SILVA, Marco. Sala de aula interativa. 6ª edição, Edições Loyola, São Paulo. 2012.

SILVA, Marizete Barbosa da; REGIANI, Anelise Maria; NICOLLI, Aline Andreia. Os plásticos e seus impactos econômicos e ambientais no ensino de Química. Revista brasileira de ensino de química, v.8, n², 2013. Disponível em: $\langle$ http://rebeq.revistascientificas.com.br/busca.php>. Acesso em: 02 mai. 2019.

SILVA, Nilma Soares; FERREIRA, André Correa; SILVEIRA, Kátia Pedroso. Ensino de Modelos para o Átomo por Meio de Recursos Multimídia em Uma Abordagem Investigativa. Química nova na escola, v.38, n², p.141-148, 2016. Disponível em:< http://qnesc.sbq.org.br/online/qnesc38_2/08-RSA-72-13.pdf>. Acesso em: 02 mai. 2019.

SILVA, José Luiz da; SILVA, Débora Antonio da; MARTINI, Cleber; DOMINGOS, Diane Cristina Araújo; LEAL, Priscila Gonçalves; FILHO, Edemar Benedetti ; FIORUCCI, Antonio Rogério. A Utilização de Vídeos Didáticos nas Aulas de Química do Ensino Médio para Abordagem Histórica e Contextualizada do Tema Vidros. Química nova na escola, v.34, nº 4, p.189-200, 2012. Disponível

em: <http://www.educadores.diaadia.pr.gov.br/arquivos/File/dezembro2012/quimica_artigos/v ideos_didaticos_aulas_quimica.pdf $>$. Acesso em: 02 mai. 2019.

SILVA, Thiago Eliel Mendonça da; BERNARDINELLI, Silvia; SOUZA, Fábio Fontana de; MATOS, Andreia Pereira; ZUIN, Vânia Gomes. Desenvolvimento e Aplicação de Webquest para Ensino de Química Orgânica: Controle Biorracional da Lagarta-do-Cartucho do Milho. Química nova na escola, v. 38, nº 1, p. 47-53, 2016. Disponível em: <http://qnesc.sbq.org.br/online/qnesc38_1/09-RSA-86-13.pdf>. Acesso em: 02 mai. 2019.

SOUZA, Dirceu Donizetti Dias de; ARROIO, Agnaldo; WEBER, Karen Cacilda. O Debate sobre Agrotóxicos na Perspectiva de uma Produção Narrativa Audiovisual Realizada por Alunos de uma Escola Pública. Revista brasileira de ensino de química, v. 8, nº1, 2013. Disponível em: $<$ http://rebeq.revistascientificas.com.br/busca.php $>$. Acesso em: 02 mai. 2019.

SOUZA, Nilcimar S.; PIRES, Cherrine K.; LINHARES, Marília P. Ensino de Química no PROEJA: Uma Proposta Integradora das Relações entre a Sala de Aula e um Fórum Virtual. Revista virtual de química, v.7, nº 3, p.992-1006, 2015. Disponível em: $\langle$ http://rvq.sbq.org.br/imagebank/pdf/v7n3a17.pdf $>$. Acesso em: 02 mai. 2019.

SOUZA, Ticiane Vieira de Paula; SOUZA, Érica Vieira de Paula; SILVA, Thiago Gomes Nepomuceno da; SILVA, Daguia de Medeiros; RIBEIRO, Maria Elenir Nobre Pinho. Proposta educativa utilizando o jogo rpg maker: estratégia de conscientização e de aprendizagem da química ambiental. Revista Holos, v.8, 2015. Disponível 
em: $\langle$ http://www2.ifrn.edu.br/ojs/index.php/HOLOS/article/view/1844>. Acesso em: 02 de mai. 2019.

VIEIRA, Fátima; RESTIVO, Maria Teresa. Novas tecnologias e educação: Ensinar a aprender, aprender a ensinar. Biblioteca Digital da Faculdade de Letras da Universidade do Porto, 2014.

VIEIRA, Rodrigo Drumond; MELO, Viviane Florentino de; BERNARDO, José Roberto da Rocha. O júri simulado como recurso didático para promover argumentações na formação de professores de física: o problema do "gato". Revista ensaio, v.16, n³, p.203-225, 2014.

WOLLMANN, Ediane Machado; BRAIBANTE, Mara Elisa Fortes. Energia Versus Poluição Atmosférica: uma oficina temática para o Ensino de Química. Revista brasileira de ensino de química, v.8, $\mathrm{n}^{\circ} 1,2013$. Disponível em: $\langle$ http://rebeq.revistascientificas.com.br/busca.php〉. Acesso em: 02 de mai. 2019.

Recebido em: 07 de setembro de 2019.

Aprovado em: 23 de dezembro de 2019. 